\title{
Utilization of direct-acting oral anticoagulation in solid organ transplant patients: A national survey of institutional practices
}

\author{
Alicia B. Lichvar ${ }^{1,2}$ (D) | Dana R. Pierce ${ }^{1}$ (D) | David Salerno ${ }^{3}$ (D) | Patrick Klem ${ }^{4}$ | \\ Georgina Waldman ${ }^{5}$ (D) | Jeong M. Park ${ }^{6}$ (D)
}

${ }^{1}$ Department of Pharmacy Practice, University of Illinois at Chicago College of Pharmacy, Chicago, IL, USA

${ }^{2}$ Department of Surgery, University of Illinois at Chicago College of Medicine, Chicago, IL, USA

${ }^{3}$ Liver Transplantation and Hepatobiliary Surgery, NewYork-Presbyterian Hospital, New York, NY, USA

${ }^{4}$ Department of Pharmacy, University of Colorado Hospital, Aurora, CO, USA

${ }^{5}$ Department of Pharmacy, Massachusetts General Hospital, Boston, MA, USA

${ }^{6}$ Department of Clinical Pharmacy, College of Pharmacy, University of Michigan, Ann Arbor, MI, USA

\section{Correspondence}

Alicia B. Lichvar, PharmD, MS, BCPS, Departments of Pharmacy Practice and Surgery, University of Illinois at Chicago, 833 S Wood Street, Chicago, IL 60612, USA. Email: alichvar@uic.edu

\begin{abstract}
The safety and efficacy of direct-acting oral anticoagulants (DOACs) and reversal strategies are not well established in the solid organ transplant population. This was a survey of pharmacists to assess DOAC and urgent reversal practices among adult transplant programs in the United States. A 27-question survey was distributed to members of transplant pharmacy organization listservs between 5/28/19 and 6/30/19. A total of 115 responses were received from kidney (43.5\%), heart (20.0\%), lung (18.3\%), liver (13.9\%), and pancreas (4.4\%) transplant programs. DOAC use prior to transplant was mostly prohibited in thoracic programs (77.3\%) but more permissive in kidney transplant programs (64.0\%). If permitted, apixaban (57.8\%) was most preferred. At transplant surgery, reversal of DOAC was performed "as needed" (20.9\%) or was not routine (18.3\%). DOAC use post-transplant was more permissive (94.3\%). A majority of responders follow FDA recommended dosing in the setting of drug-drug interactions (51.1\%). Major factors influencing DOAC prescribing decisions included renal function, drug-drug interactions, and insurance. High clinical practice variability exists regarding DOAC utilization and urgent reversal strategies in pre-, peri-, and post-transplant stages. While more research is needed to refine the clinical landscape, many institutions are using DOAC therapy under the perception that they pose a similar risk of bleeding compared to a non-transplant population.
\end{abstract}

\section{KEYWORDS}

coagulation and hemostasis, drug interaction, pharmacodynamics, pharmacokinetics, survey

\section{1 | INTRODUCTION}

Direct-acting oral anticoagulants (DOACs) have been approved for use in the United States since 2010. ${ }^{1-4}$ Their efficacy and safety have been demonstrated in large multinational trials for the prevention and treatment of venous thromboembolism (VTE) and for the prevention of thrombosis in non-valvular atrial fibrillation (AF). ${ }^{5,6}$ Compared to vitamin $\mathrm{K}$ antagonist therapy, DOACs offer the benefits of limited drug interactions, standard dosing, lack of dietary constraints, and unnecessary therapeutic drug monitoring. ${ }^{7}$
While DOACs have changed the anticoagulation landscape, there is a paucity of data in specialty populations. Particularly, solid organ transplant recipients demonstrate unique pharmacokinetic considerations regarding renal and hepatic function as well as drug-drug interactions. ${ }^{8}$ Transplant recipients also experience AF and VTE at a higher rate than the general population, making DOAC therapy an inciting treatment option for providers over traditional vitamin $\mathrm{K}$ antagonist therapy despite the lack of prospective data., ${ }^{9,10}$ Currently, the data examining DOAC utilization in transplant recipients is limited to single-center retrospective assessments. ${ }^{8}$ 
Managing DOAC therapies at the time of transplantation can be challenging. While guidance exists regarding DOAC therapy interruption in the context of elective surgery, these clinical recommendations were based on data excluding solid organ transplant recipients from analysis. ${ }^{11-13}$ Furthermore, anticoagulation reversal options are important to consider in order to appropriately manage patients in the setting of urgent surgeries or even adverse major bleeding events. The currently FDA-approved reversal agents, idarucizumab and andexanet alfa, have primarily been utilized in the setting of acute major hemorrhage. ${ }^{14,15}$ Transplant patients often require urgent procedures or allograft biopsies in the setting of altered graft function and/or potential drug-drug interactions, which can complicate the pharmacokinetics of DOAC therapy and reversal management.

Overall, limited data exist on the safe use of DOAC therapy after organ transplant, which has created significant clinical practice heterogeneity. In the advent of DOACs coming to the forefront of anticoagulation modalities, transplant centers are faced with the need to reflect and even protocolize their approach to this class of medications. Therefore, the purpose of this transplant pharmacist survey study was to assess DOAC utilization and urgent reversal practices among adult transplant programs in the United States.

\section{2 | MATERIALS AND METHODS}

A 27-question online survey was developed, consisting of 20 multiple-choice and 7 open-ended questions (survey questions detailed in the Supplemental Information). The survey contained branching logic, depending on the allowance of DOAC therapy pre- and post-transplantation and focused on the practice patterns of DOAC therapy in the pre-, peri-, and post-transplant phases. Management and approach to reversal at the time of transplant surgery was also evaluated. All revisions were vetted across all investigators until a final survey instrument was agreed upon by the group. The survey was then pilot tested by external practitioners not involved with the study, and additional revisions were incorporated. The survey was completed using a Qualtrics ${ }^{\circledR}$ platform (Qualtrics, Provo, UT).

Surveys were distributed via the American Society of Transplantation Transplant Pharmacy Community of Practice listserv, the American College of Clinical Pharmacy Immunology/ Transplantation Practice and Research Network listserv, and the International Society of Heart and Lung Transplantation Scientific Council on Pharmacy and Pharmacology listserv. Pharmacist members were invited to voluntarily submit a survey response per organ-specific program of their current practice. There was not individual contact with transplant programs. Each center was allowed to submit a single response per organ type. All allograft types were permitted to describe the national landscape and practice variation in DOAC therapy utilization.

The study was approved by the University of Illinois at Chicago Institutional Review Board, and the survey remained open between May 28, 2019 and June 30, 2019. All surveys that were more than $30 \%$ complete were included in the analysis.

\section{3 | RESULTS}

A total of 115 responses were received and 20 (17.4\%) were partial responses. Fifty (43.5\%) were kidney, 23 (20.0\%) were heart, 21 (18.3\%) were lung, 16 (13.9\%) were liver, and 5 (4.4\%) were SPK/ $\mathrm{PAK} /$ pancreas alone. A total of 72 transplant centers provided responses for 115 organ-specific programs. These survey responses represent $34.1 \%$ of 211 adult transplant centers and $15 \%$ of 768 practicing adult organ programs identified via the Organ Procurement and Transplantation Network. ${ }^{16}$ Overall, a majority of programs performed at least 50 organ transplants per year (74/115, 64.3\%). Renal transplant programs drove this response with $20 / 50$ (40\%) of responders reporting 101-200 kidneys and 16/50 (32\%) performing over 200 kidneys in 2018. A majority of the liver transplant centers were high-volume with $8 / 16$ (50\%) of responders reporting $>100$ liver transplants per year. Inversely, a majority of thoracic program responders reported having performed $<50$ transplants per year (27/44, 61.4\%) within their respective organ. Consistencies between survey responses were maintained when compared between large and small kidney transplant programs. Summarized survey results are detailed in Table 1 with organ-specific data being included in Supplemental Information (Table S1).

\section{1 | Pre-Transplant DOAC Utilization}

Prior to transplant, $43 / 115$ (37.4\%) of the responders allow patients to remain on DOAC therapy. Thirty-two out of fifty (64.0\%) kidney transplant programs allow patients to remain on DOAC therapy while on the transplant waitlist with 15/50 (30.0\%) kidney transplant programs allowing it for candidates for planned living donor transplant. For liver transplantation, there is typically no consistent approach for allowing patients to remain on DOAC therapy while on the waitlist (7/16, 43.8\%), and 4/16 (25.0\%) responded they continue DOAC therapy while on the waitlist. The majority of heart (18/23, 78.3\%) and lung $(16 / 21,76.2 \%)$ transplant programs do not allow patients to remain on DOAC therapy while on the waitlist.

Apixaban (26/45, 57.8\%) was the most preferred agent for waitlist transplant candidates, while $12 / 45(26.7 \%)$ of responding programs had no preferred agent. Responders from abdominal transplant programs $(23 / 36,63.9 \%)$ preferred apixaban, while thoracic programs split between dabigatran $(4 / 9,44.4 \%)$ and apixaban (3/9, 33.3\%). Of those with a preferred agent, $12 / 27$ (44.4\%) responded that they will switch to the preferred DOAC while the patient is on the transplant waitlist. When DOAC utilization was not allowed, warfarin was typically the preferred agent $(36 / 49,73.5 \%)$.

\section{2 | Peri-Transplant DOAC Reversal}

DOAC reversal was not common during transplant surgery. Of the 115 responders, only 9 programs $(7.8 \%)$ reported a routine use of DOAC reversal agents, of which 7 were thoracic organ transplant 
TABLE 1 Summarized DOAC Survey Results

\begin{tabular}{|c|c|}
\hline \multicolumn{2}{|l|}{ Variable } \\
\hline Total number of responses ${ }^{a}$ & 115 \\
\hline \multicolumn{2}{|l|}{ Organ discipline, n (\%) } \\
\hline Lung & $21(18.3)$ \\
\hline Kidney & $50(43.5)$ \\
\hline Liver & $16(13.9)$ \\
\hline \multicolumn{2}{|l|}{ Number of transplants per year, $\mathrm{n}(\%)$} \\
\hline$<50$ organs & $41(35.7)$ \\
\hline $50-100$ organs & $26(22.6)$ \\
\hline $101-200$ organs & $30(26.1)$ \\
\hline Pharmacist evaluation/discussion prior to selection committee review and listing & $98(85.2)$ \\
\hline Pharmacist evaluation/discussion prior to transplantation after listing & $38(33.0)$ \\
\hline Pharmacist is not involved in management of DOAC therapy & $13(11.3)$ \\
\hline Other role, not otherwise specified & $9(7.8)$ \\
\hline \multicolumn{2}{|c|}{ Organ programs that allow for patients on the transplant waitlist to remain on DOAC therapy, $\mathrm{n}(\%)$} \\
\hline Yes & $28(24.4)$ \\
\hline No & $49(42.6)$ \\
\hline Yes, only for living donor transplant candidates & $15(13.0)$ \\
\hline No consistent approach within the program & $23(20.0)$ \\
\hline \multicolumn{2}{|l|}{ Organ Programs that allow for DOAC therapy post-transplant, $\mathrm{n}(\%)$} \\
\hline Yes & 100/106 (94.3) \\
\hline No & $6 / 106(5.7)$ \\
\hline \multicolumn{2}{|c|}{ Factors influencing prescribing or recommending specific DOAC therapy post-transplant (multiple options able to be selected), $\mathrm{n}$ (\%) } \\
\hline Patient preference & $49 / 95(51.6)$ \\
\hline Insurance coverage & $64 / 95(67.4)$ \\
\hline Patient renal function & $75 / 95(79.0)$ \\
\hline Patient body habitus & $24 / 95(25.3)$ \\
\hline Concomitant drug-drug interactions & 74/95 (77.9) \\
\hline Thrombophilia & $9 / 95(9.5)$ \\
\hline Other, not otherwise specified & $22 / 95(23.2)$ \\
\hline \multicolumn{2}{|l|}{ Perceived risk of DOAC use post-transplant (multiple options able to be selected), n (\%) } \\
\hline Similar risk to non-transplant population & $44(38.3)$ \\
\hline Increased risk for bleeding compared to non-transplant population & $38(33.0)$ \\
\hline Limited data in the context of DOAC use in this population & $74(64.3)$ \\
\hline Need to intensify immunosuppression drug monitoring for drug interactions & $7(6.1)$ \\
\hline Other, not otherwise specified & $12(10.4)$ \\
\hline
\end{tabular}

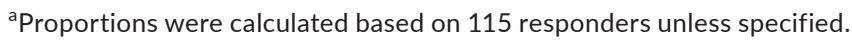


programs. Twenty-one (18.3\%) do not routinely reverse DOAC therapy and 24 responders (20.9\%) utilize reversal agents on an "as needed" basis. Most of the responders (53.0\%) reported that patients were not brought to transplant while maintained on DOAC therapy.

A total of 25 responders commented about DOAC-specific reversal strategies (dabigatran $n=8$, apixaban $n=7$, rivaroxaban $n=5$, edoxaban $n=5)$. Idarucizumab $(6 / 8,75.0 \%)$ was the most routinely used agent for dabigatran reversal. Similarly, 14/17 (82.4\%) responders report using the 4-factor prothrombin complex concentrate (4F-PCC) for reversal of factor Xa inhibitors. If the programs do not routinely use DOAC reversal, 15/93 (16.1\%) responders report delaying or canceling transplantation due to inadequate time for holding DOAC therapy. This practice was less commonly observed in thoracic transplant programs $2 / 34$ (5.9\%) compared to kidney $10 / 40$ (25.0\%), pancreas $1 / 5$ (20.0\%), or liver $2 / 14$ (14.3\%) transplant programs. Smaller kidney transplant programs $(<100$ transplants per year) reported delaying or canceling transplantation in the setting of DOAC therapy $(5 / 10,50 \%)$ compared to larger kidney transplant programs (25/30, 83.3\%).

At the time of transplantation, 30/102 (29.4\%) responders report using one or more type of laboratory monitoring tool to assess safety prior to transplant surgery. The most commonly used monitoring parameters were aPTT (13/30, 43.0\%), PT/INR (11/30, 36.7\%), and anti-Xa monitoring (10/30, 33.3\%). Thoracic transplant programs $(17 / 30,56.7 \%)$ comprised the largest group using laboratory monitoring prior to transplant surgery relative to kidney $(10 / 30,33.3 \%)$, liver $(2 / 30,6.7 \%)$, or pancreas $(1 / 30,3.3 \%)$ programs.

\section{3 | Post-Transplant DOAC Utilization}

Out of 106 responses, 100 (94.3\%) allow DOAC therapy in the posttransplant setting. Time to initiation or re-initiation of DOAC after transplantation was not protocolized (37/90, 41.1\%); furthermore, 44/89 (49.4\%) do not have a cutoff for $\mathrm{CrCl}$ threshold for DOAC initiation.

In the setting of drug-drug interactions, 45/88 (51.1\%) do not deviate from the dosing contained within the prescribing information. Of the centers that reduce DOAC dosing outside of the FDA labeling information, 18/32 (56.3\%) will reduce for one drug-drug interaction and $14 / 32$ (43.8\%) will consider DOAC dose reduction in the setting of two or more drug-drug interactions.

A total of $42 / 96$ responders (43.8\%) avoid DOAC use in the setting of cyclosporine therapy, whereas $13 / 96$ (13.5\%) would reduce DOAC dose with concomitant use of cyclosporine. For patients on tacrolimus, 76/103 (73.8\%) do not adjust DOAC dose. Many centers allowed concomitant aspirin utilization with DOAC therapy (27/33, 81.8\%). Similarly, a majority of patients on DOAC therapy are also permitted to be on non-aspirin anti-platelet therapy (21/33, 63.6\%).

Patient renal function (75/95, 79.0\%), concomitant drug-drug interactions (74/95, 77.9\%), and patient insurance coverage (64/95,
67.4\%) were major factors that influenced prescribing decisions regarding DOAC therapy.

\subsection{Role of the Transplant Pharmacist}

A total of $102 / 115(88.7 \%)$ responders stated that a transplant pharmacist is involved in the management of DOAC utilization prior to transplant and during waitlist maintenance. Transplant pharmacists are frequently involved in the evaluation and discussion of the management of DOAC therapy prior to transplant and listing (98/115, $85.2 \%)$. Fewer pharmacists $(38 / 115,33.0 \%)$ are involved in the DOAC management of patients on the transplant waitlist.

While a majority of pharmacist responders (64.3\%) acknowledge that transplant-specific data on DOAC use are lacking, opinions on perceived bleeding risks of DOAC in the transplant population were split between similar (38.3\%) vs increased (33.0\%) compared to the non-transplant population.

\section{4 | DISCUSSION}

Solid organ transplant recipients are more likely to require anticoagulation for either AF or VTE comparatively to the general population. ${ }^{9,10}$ However, no controlled trials exist investigating DOAC use in solid organ transplant recipients. In addition, there is significant variability in the reported drug-drug interactions and corresponding recommendations for the DOAC dose adjustments. ${ }^{8}$ As such, health care providers need to make treatment decisions based on limited data from observational cohorts and individual practice experiences. $^{8,17}$ This is the first study to characterize the current use of DOAC therapy and reversal strategies in solid organ transplant programs across the United States.

The results of our survey highlight a lack of uniformity regarding DOAC therapy in the pre-, peri-, and post-transplant phases of care. In the pre-transplant phase, $37.4 \%$ of responders allow patients to remain on a DOAC while on the waitlist. Kidney transplant programs predominately drive this response, as $77 \%$ of thoracic programs do not allow DOAC use while on the waitlist. For those centers allowing DOAC use while on the waitlist, apixaban is the preferred agent.

This preference is likely based on the pharmacokinetic properties of the DOACs, as apixaban is less reliant on kidneys for clearance and may be utilized for patients with severe renal impairment or dialysis. ${ }^{1}$ Rivaroxaban does have significant renal clearance, increasing drug exposure up to $64 \%$ when patients with severe renal impairment were compared to healthy volunteers. ${ }^{4}$ However, registry data have shown a lower rate of stroke and systemic embolism with rivaroxaban with no difference in bleeding when compared to warfarin in patients with renal impairment. ${ }^{18}$ Dabigatran is primarily eliminated via the kidneys and generally not recommended for use in patients with renal insufficiency. ${ }^{2}$ Table 2 highlights the pharmacokinetic differences of DOAC agents. 
Peri-operatively, only $8 \%$ of programs report routinely reversing DOACs prior to transplant. Consistent with expectations, reversal of dabigatran has been primarily with idarucizumab (75\% of responders), and 4F-PCC has been utilized for factor Xa inhibitors. None of our survey responders report the use of andexanet alfa, as the FDA did not approve full commercial launch of this agent until January 2019 and the product was not widely distributed at the time of the survey. Small case series have described idarucizumab for dabigatran reversal in transplant recipients. ${ }^{19-21}$ However, no data exists for andexanet alfa, in the reversal of apixaban or rivaroxaban in a transplant population.

Non-specific reversal agents, predominantly 4F-PCC, were reported by programs necessitating factor $\mathrm{Xa}$ inhibitor reversal.
However, neither 4F-PCC nor activated prothrombin complex concentrate (aPCC) has FDA-approved indications for DOAC reversal. ${ }^{22,23}$ Nevertheless, these observed reversal practices are in line with recent recommendations from The Anticoagulation Forum which recommend either idarucizumab or aPCC for dabigatran reversal and andexanet alfa or 4F-PCC for factor Xa inhibitor reversal, depending on the availability of selected specific reversal agent. ${ }^{13}$ While studies have demonstrated that both 4F-PCC and aPCC are non-specific options for DOAC reversal, there is no data within solid organ transplant or comparative data to idarucizumab or andexanet alfa at this time. Table 3 details currently available DOAC reversal options.

TABLE 2 Summary of DOAC therapy options

\begin{tabular}{|c|c|c|c|c|}
\hline DOAC & $\begin{array}{l}\text { APIXABAN } \\
\left(\text { ELIQUIS }^{\circledR}\right)^{1}\end{array}$ & $\begin{array}{l}\text { DABIGATRAN } \\
\left(\text { PRADAXA }^{\circledR}\right)^{2}\end{array}$ & $\begin{array}{l}\text { EDOXABAN } \\
\left(\text { SAVAYSA }^{\circledR}\right)^{3}\end{array}$ & RIVAROXABAN (XARELTO $\left.{ }^{\circledR}\right)^{4}$ \\
\hline $\begin{array}{l}\text { Mechanism of } \\
\text { Action }\end{array}$ & Factor Xa inhibitor & $\begin{array}{l}\text { Direct thrombin } \\
\text { inhibitor }\end{array}$ & $\begin{array}{l}\text { Factor Xa } \\
\text { inhibitor }\end{array}$ & Factor Xa inhibitor \\
\hline \multicolumn{5}{|c|}{ Indications and recommended dosing } \\
\hline $\begin{array}{l}\text { Prevention of } \\
\text { stroke and } \\
\text { systemic } \\
\text { embolism } \\
\text { in non- } \\
\text { valvular atrial } \\
\text { fibrillation }\end{array}$ & $\begin{array}{l}5 \mathrm{mg} \text { PO BID } \\
\text { Dose adjusted to } 2.5 \mathrm{mg} \\
\text { PO BID for patients with } \\
\text { at least } 2 \text { of the following: } \\
\geq 80 \text { y old, weight } \leq 60 \mathrm{~kg} \text {, or } \\
\mathrm{SCr} \geq 1.5 \mathrm{mg} / \mathrm{dL}\end{array}$ & 150 mg PO BID & $\begin{array}{l}60 \mathrm{mg} P O \text { daily } \\
\text { CrCL } 30-50 \mathrm{~mL} / \\
\text { min: } 30 \mathrm{mg} \text { PO } \\
\text { daily }\end{array}$ & $\begin{array}{l}20 \mathrm{mg} \text { PO daily with food } \\
\mathrm{CrCL} 30-50 \mathrm{~mL} / \mathrm{min}: 15 \mathrm{mg} \text { PO daily } \\
\text { with food }\end{array}$ \\
\hline $\begin{array}{l}\text { VTE prevention } \\
\text { post hip } \\
\text { or knee } \\
\text { replacement }\end{array}$ & $2.5 \mathrm{mg}$ PO BID & 220 mg PO daily & $\mathrm{N} / \mathrm{A}$ & 10 mg PO daily \\
\hline $\begin{array}{l}\text { DVT/PE } \\
\text { treatment }\end{array}$ & $\begin{array}{l}10 \text { mg PO BID X } 7 \mathrm{~d}, 5 \mathrm{mg} \text { PO } \\
\text { BID thereafter }\end{array}$ & $\begin{array}{l}150 \text { mg PO BID after } \\
5-10 \text { d of initial therapy } \\
\text { with a parenteral } \\
\text { anticoagulant }\end{array}$ & $\begin{array}{l}60 \text { mg PO daily } \\
\text { after } 5-10 \mathrm{~d} \\
\text { of initial } \\
\text { therapy with } \\
\text { a parenteral } \\
\text { anticoagulant } \\
\mathrm{CrCL} 35-50 \mathrm{~mL} / \\
\text { min or < } 60 \mathrm{~kg} \text { : } \\
30 \mathrm{mg} \text { PO daily }\end{array}$ & $\begin{array}{l}15 \mathrm{mg} \text { PO BID with food X } 21 \mathrm{~d} \text {, } \\
\text { then } 20 \mathrm{mg} \text { PO daily with food }\end{array}$ \\
\hline $\begin{array}{l}\text { Reduction in } \\
\text { the risk of } \\
\text { recurrence of } \\
\text { DVT/PE }\end{array}$ & $2.5 \mathrm{mg}$ PO BID & 150 mg PO BID & $\mathrm{N} / \mathrm{A}$ & 10 mg PO daily with or without food \\
\hline \multicolumn{5}{|c|}{ Dosing in special populations } \\
\hline Renal dosing & $\begin{array}{l}\text { AF dosing: dose adjusted to } \\
2.5 \mathrm{mg} \text { PO BID for patients } \\
\text { with at least } 2 \text { of the following: } \\
80 \text { y old, weight } \leq 60 \mathrm{~kg} \text {, or } \\
\mathrm{Cr} \geq 1.5 \mathrm{mg} / \mathrm{dL}\end{array}$ & $\begin{array}{l}\mathrm{CrCl} 15-30 \mathrm{~mL} / \mathrm{min}: \\
75 \mathrm{mg} \text { PO BID }\end{array}$ & $\begin{array}{l}\mathrm{CrCl}>95 \mathrm{~mL} / \mathrm{min}: \\
\text { Do not use } \\
\mathrm{CrCl} 15-30 \mathrm{~mL} / \\
\text { min: } 30 \mathrm{mg} \mathrm{PO} \\
\text { daily }\end{array}$ & $\begin{array}{l}\text { AF dosing: } \mathrm{CrCl}<50 \mathrm{~mL} / \mathrm{min}: 15 \mathrm{mg} \\
\text { PO daily } \\
\text { Other indications: Avoid with } \\
\mathrm{CrCl}<30 \mathrm{~mL} / \mathrm{min}\end{array}$ \\
\hline $\begin{array}{l}\text { Hepatic } \\
\text { impairment }\end{array}$ & $\begin{array}{l}\text { Moderate (Child-Pugh B): Use } \\
\text { caution } \\
\text { Severe (Child-Pugh C): Avoid use }\end{array}$ & $\begin{array}{l}\text { Severe (Child-Pugh } \\
\text { C): Caution-no } \\
\text { information available }\end{array}$ & $\begin{array}{l}\text { Moderate or } \\
\text { Severe (Child- } \\
\text { Pugh B and C): } \\
\text { Avoid use }\end{array}$ & $\begin{array}{l}\text { Child-Pugh B or C or any degree of } \\
\text { hepatic coagulopathy: Avoid use }\end{array}$ \\
\hline $\begin{array}{l}\mathrm{CrCl} \text { exclusion in } \\
\text { clinical trials }\end{array}$ & $<25 \mathrm{~mL} / \mathrm{min}$ & $<30 \mathrm{~mL} / \mathrm{min}$ & $<30 \mathrm{~mL} / \mathrm{min}$ & $<30 \mathrm{~mL} / \mathrm{min}$ \\
\hline Renal excretion & $27 \%$ & $80 \%$ & $50 \%$ & $36 \%$ \\
\hline
\end{tabular}


Furthermore, $69.5 \%$ of responders reported not using laboratory monitoring (eg, PT, aPTT, thromboelastometry/rotational thromboelastometry) to assess safety prior to undergoing transplant. This finding matches the poor performance of these tests to accurately predict the degree of anticoagulation present. ${ }^{11}$ Interestingly, 16\% of responders report the cancelation of transplant surgery due to bleeding concerns at the time of transplantation. This may reflect the inability to utilize more specific quantitative measures such as dilute thrombin time or ecarin clotting time for dabigatran or calibrated anti-factor Xa levels. ${ }^{11}$

While concerns persist around the safety of DOACs before and at the time of transplant surgery, nearly all responders (94\%) reported using a DOAC in the post-transplant setting, suggesting that these agents are viewed similarly to warfarin therapy when chronic oral anticoagulation therapy is necessary after transplant. The majority of responders (51\%) follow the FDA prescribing information for dose adjustments, but of those that do not, $97 \%$ of responders make empiric dose adjustments for drug-drug interactions. Continued assessment for dose adjustments is paramount to DOACs in post-transplant patients. Lichvar et al found that $60 \%$ of patients had empiric DOAC dose reduction for known drug-drug interactions, and $46 \%$ of patients who did not have empiric dose adjustment required DOAC dose adjustment while on therapy due to changes in renal function. ${ }^{17}$ These findings highlight that while therapeutic drug monitoring is not needed, close follow-up is necessary to ensure safe clinical utilization of DOAC therapy.

There is a critical role for the transplant pharmacotherapy specialist in the use of DOACs in this patient population. Eighty-five percent of pharmacists responded that they participate in the evaluation or discussion of patients on DOACs in the pre-transplant period. Pharmacist involvement in outpatient DOAC management leads to improved appropriate DOAC dosing and medication adherence, highlighting the role of pharmacist monitoring in these patients. ${ }^{24}$

Nearly half (43.8\%) of respondents avoid DOACs concomitantly with cyclosporine driven predominantly by kidney transplant programs; whereas, $13.5 \%$ reduce the dose empirically with cyclosporine. The hesitancy to utilize cyclosporine in conjunction with DOACs stems from a case series describing higher rivaroxaban trough concentrations in those patients on cyclosporine (131.7 $\pm 119.5 \mathrm{ng} /$ $\mathrm{mL}$ ) versus those patients on tacrolimus $(20.3 \pm 14.4 \mathrm{ng} / \mathrm{mL}){ }^{25}$ Remarkably, the mean trough concentration for rivaroxaban in those patients on concurrent cyclosporine was higher than the reported reference range for trough concentrations for rivaroxaban (6-87 ng/ $\mathrm{mL}$ ); moreover, this was in the setting of relatively low cyclosporine trough concentrations $(69 \pm 41 \mathrm{ng} / \mathrm{mL}){ }^{25}$ Therefore, the rivaroxaban-cyclosporine interaction may be clinically more relevant compared to rivaroxaban-tacrolimus.

Eighty-two percent of responders reported they allow concomitant aspirin and $64 \%$ reported use with concomitant non-aspirin anti-platelet agents in combination with DOACs. The use of anti-platelet agents concomitantly with DOACs is a hot topic as patients with multiple comorbidities and indications for anti-platelet agents are increasingly being transplanted. ${ }^{26} \mathrm{~A}$ meta-analysis of the
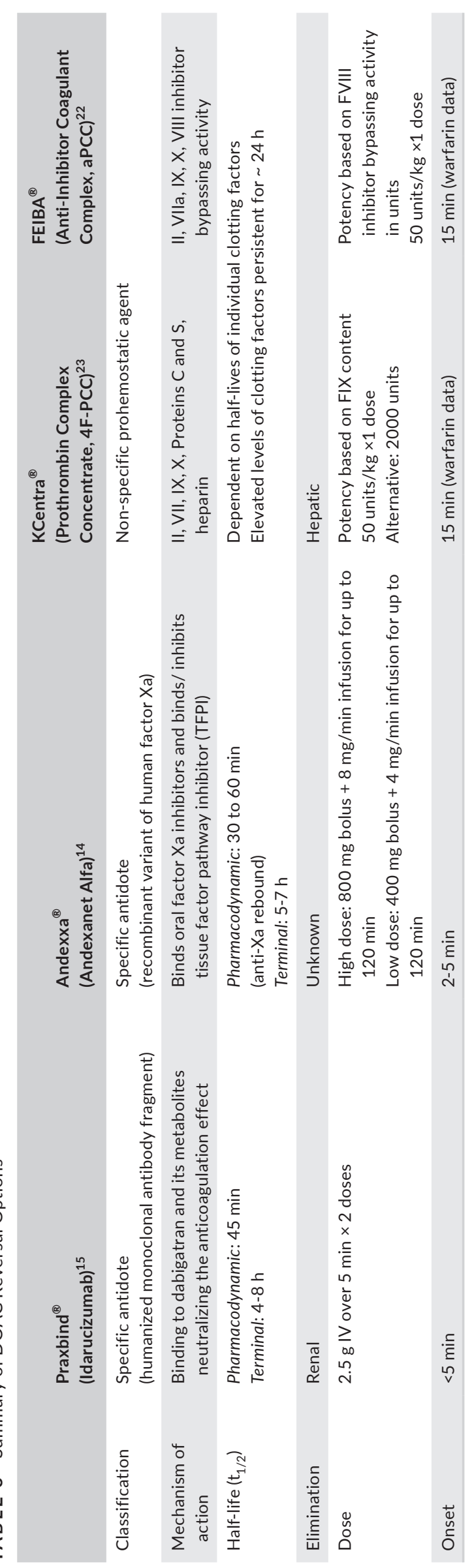
four registration trials for dabigatran, rivaroxaban, apixaban, and edoxaban in AF failed to demonstrate a difference in major bleeding in patients who received single anti-platelet therapy with either a DOAC or warfarin. ${ }^{27}$ However, registry data from Canada were able to demonstrate a lower rate of major bleeding, with the exception of gastrointestinal bleeding, for those patients utilizing a single anti-platelet plus DOACs versus warfarin. ${ }^{28}$ Clinicians should be attentive to the potential increasing risk of bleeding for those patients utilizing single or dual anti-platelet therapy in combination with DOAC therapy versus DOAC alone.

A significant strength of our study is that this was an all pharmacist-based survey that allowed for consistent interrater variability. Additionally, this is the first study of its kind to describe DOAC clinical practice trends across transplant centers within the United States. In this way, there is shared knowledge regarding the approach to DOAC therapy across the specialty. This may encourage institutions to reflect on their approach to novel anticoagulation and promote others to share their experiences through peer-reviewed publications or abstracts.

There are several limitations with this study. As with any volunteer survey, there is a potential selection bias including only those centers that feel strongly (either positively or negatively) about DOAC use in transplant candidates or recipients, which could have influenced the findings. Although the diversity in the responses based on center volume, location, and organ discipline for each responder ameliorate this bias concern. Second, the response rate for this survey was $34.1 \%$, which is low considering the number of institutions within the United States and the diversity of organ programs represented at each center. However, previous literature has reported an average rate of $39.6 \%$ for internet-based surveys. ${ }^{29}$ The survey was distributed to only transplant pharmacists; however, other members of the transplant multidisciplinary team may have opinions that differ from the transplant pharmacist completing the survey. Despite this, the transplant pharmacists are likely to be involved with or familiar with DOAC management at their respective institutions as the pharmacotherapy experts. Finally, no rates of VTE or bleeding were collected in our survey; therefore, we are unable to links variation in practice patterns to clinical outcomes. However, we felt that the inclusion of clinical outcomes may have decreased the survey response rate substantially and limited our ability to understand the various practice using DOACs nationally.

\section{5 | CONCLUSIONS}

In conclusion, this all pharmacist-based survey evaluated the practice patterns of DOAC therapy in the pre-, peri-, and post-transplant phases in solid organ transplant recipients. There was a high rate of variability in DOAC management practices. The majority of centers do not allow DOAC use while on the waitlist or have a protocol for reversal at the time of transplant surgery. Nearly, all centers reported utilizing the DOACs in the post-transplant phase, with the majority following the recommendations from the package insert regarding dose adjustments for end organ function and drug-drug interactions. DOAC use post-transplant needs to be evaluated in controlled studies to further elucidate the purported perils in this high-risk patient population.

\section{ACKNOWLEDGEMENTS}

We thank the following organizations for allowing survey distribution: American College of Clinical Pharmacy Immunology and Transplant Practice and Research Network, International Heart and Lung Transplant Pharmacy Forum, and the American Society of Transplantation Transplant Pharmacy Community of Practice.

\section{CONFLICT OF INTEREST}

Nothing to disclose.

\section{AUTHORS CONTRIBUTIONS}

Alicia B. Lichvar, Dana R. Pierce, David Salerno, Patrick Klem, Georgina Waldman, and Jeong M. Park: Participated in research design, participated in the writing of the paper, participated in the performance of the research. Alicia B. Lichvar, Dana R. Pierce, David Salerno: participated in data analysis.

\section{ORCID}

Alicia B. Lichvar (iD https://orcid.org/0000-0003-3804-6517

Dana R. Pierce iD https://orcid.org/0000-0002-6074-7267

David Salerno (iD https://orcid.org/0000-0002-5450-3995

Georgina Waldman (iD https://orcid.org/0000-0003-3291-4491

Jeong M. Park iD https://orcid.org/0000-0002-7961-494X

\section{REFERENCES}

1. Eliquis $₫$ [package insert] Princeton NB-MSC

2. Pradaxa ${ }^{\circledR}$ [package insert] Ridgefield CBIP, Inc.; 2018.

3. Savaysa ${ }^{\circledR}$ [package insert] Parsippany NDSC, Ltd.; 2017.

4. Xarelto ${ }^{\circledR}$ [package insert] Titusville NJO, LLC; 2019.

5. Gomez-Outes A, Terleira-Fernandez Al, Lecumberri R, Suarez-Gea $M L$, Vargas-Castrillon E. Direct oral anticoagulants in the treatment of acute venous thromboembolism: a systematic review and meta-analysis. Thromb Res. 2014;134(4):774-782.

6. Ruff CT, Giugliano RP, Braunwald E, et al. Comparison of the efficacy and safety of new oral anticoagulants with warfarin in patients with atrial fibrillation: a meta-analysis of randomised trials. Lancet. 2014;383(9921):955-962.

7. Lee LH. DOACs - advances and limitations in real world. Thromb J. 2016;14(1):17.

8. Salerno DM, Tsapepas D, Papachristos A, et al. Direct oral anticoagulant considerations in solid organ transplantation: a review. Clin Transplant. 2017;31(1):e12873.

9. Lentine KL, Schnitzler MA, Abbott KC, et al. Incidence, predictors, and associated outcomes of atrial fibrillation after kidney transplantation. Clin J Am Soc Nephrol. 2006;1(2):288-296.

10. Saez-Gimenez B, Berastegui C, Loor K, et al. Deep vein thrombosis and pulmonary embolism after solid organ transplantation: an unresolved problem. Transplant Rev. 2015;29(2):85-92.

11. Doherty JU, Gluckman TJ, Hucker WJ, et al. 2017 ACC expert consensus decision pathway for periprocedural management of anticoagulation in patients with nonvalvular atrial fibrillation: a report of the American College of Cardiology Clinical Expert Consensus Document Task Force. J Am Coll Cardiol. 2017;69(7):871-898. 
12. Douketis JD, Spyropoulos AC, Anderson JM, et al. The Perioperative Anticoagulant Use for Surgery Evaluation (PAUSE) Study for Patients on a Direct Oral Anticoagulant Who Need an Elective Surgery or Procedure: design and rationale. Thromb Haemost. 2017;117(12):2415-2424.

13. Cuker A, Burnett A, Triller D, et al. Reversal of direct oral anticoagulants: guidance from the Anticoagulation Forum. Am J Hematol. 2019;94(6):697-709.

14. Andexxa ${ }^{\circledR}[$ package Insert]. South San Francisco CPP.

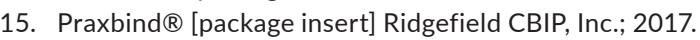

16. Sharing OPaTNUNfO. Membership Directory.

17. Lichvar AB, Moore CA, Ensor CR, McDyer JF, Teuteberg JJ, Shullo MA. Evaluation of direct oral anticoagulation therapy in heart and lung transplant recipients. Prog Transplant. 2016;26(3):263-269.

18. Weir MR, Haskell L, Berger JS, et al. Evaluation of clinical outcomes among nonvalvular atrial fibrillation patients treated with rivaroxaban or warfarin, stratified by renal function. Clin Nephrol. 2018;89(5):314-329.

19. Tralhao A, Aguiar C, Ferreira J, et al. Dabigatran reversal with idarucizumab in a patient undergoing heart transplantation: first European report. Thromb J. 2017;15:23.

20. Jozwik A, Lisik W, Czerwinski J, Kosieradzki M. Simultaneous pancreas-kidney transplantation in a patient with heparin-induced thrombocytopenia on dabigatran therapy. Ann Transplant. 2018;23:232-235.

21. Van Keer JM, Vanassche T, Droogne W, et al. Idarucizumab for the reversal of dabigatran in patients undergoing heart transplantation. Eur J Heart Fail. 2019;21(1):129-131.

22. FIEBA [prescribing information] Lexington MBUI.

23. KCentra ${ }^{\circledR}$ [prescribing information] Kankakee ICBL.

24. Ashjian E, Kurtz B, Renner E, Yeshe R, Barnes GD. Evaluation of a pharmacist-led outpatient direct oral anticoagulant service. Am J Health-Syst Pharm. 2017;74(7):483-489.

25. Wannhoff A, Weiss KH, Schemmer P, Stremmel W, Gotthardt DN. Increased levels of rivaroxaban in patients after liver transplan- tation treated with cyclosporine A. Transplantation. 2014;98(2): e12-e13.

26. Dogan A, Ozdemir E, Kahraman S, Acil T, Saltan Y, Kurtoglu N. Impact of early (3 months) dual antiplatelet treatment interruption prior to renal transplantation in patients with second-generation DES on perioperative stent thrombosis and MACEs. Anatol J Cardiol. 2017;18(6):391-396.

27. Bennaghmouch $\mathrm{N}$, de Veer A, Bode K, et al. Efficacy and safety of the use of non-vitamin $\mathrm{K}$ antagonist oral anticoagulants in patients with nonvalvular atrial fibrillation and concomitant aspirin therapy: a meta-analysis of randomized trials. Circulation. 2018;137(11):1117-1129.

28. Douros A, Renoux C, Yin H, Filion KB, Suissa S, Azoulay L. Concomitant use of direct oral anticoagulants with antiplatelet agents and the risk of major bleeding in patients with nonvalvular atrial fibrillation. Am J Med. 2019;132(2):191-199.e112.

29. Cook C, Heath F, Thompson RL. A Meta-analysis of response rates in web- or internet-based surveys. Educ Psychol Measur. 2000;60(6):821-836.

\section{SUPPORTING INFORMATION}

Additional supporting information may be found online in the Supporting Information section.

How to cite this article: Lichvar AB, Pierce DR, Salerno D, Klem P, Waldman G, Park JM. Utilization of direct-acting oral anticoagulation in solid organ transplant patients: A national survey of institutional practices. Clin Transplant.

2020;34:e13853. https://doi.org/10.1111/ctr.13853 